\title{
A Design for a High Voltage Magnet Coil Ringer Test Set
}

\author{
W. Koska \\ Fermi National Accelerator Laboratory \\ P.O. Box 500, Batavia, Illinois 60510 \\ R. Sims \\ SSC Laboratory \\ 2550 Beckleymeade Avenue, Dallas, Texas 75237
}

April 1992

Presented at the Fourth Annual 1992 International Industrial Symposium on the Super Collider, New Orleans, Louisiana, March 4-6, 1992. 


\section{Disclaimer}

This report was prepared as an account of work sponsored by an agency of the United States Government. Neither the United States Government nor any agency thereof, nor any of their employees, makes any warranty, express or implied, or assumes any legal liability or responsibility for the accuracy, completeness, or usefulness of any information, apparatus, product, or process disclosed, or represents that its use would not infringe privately owned rights. Reference herein to any specific commercial product, process, or service by trade name, trademark, manufacturer, or otherwise, does not necessarily constitute or imply its endorsement, recommendation, or favoring by the United States Government or any agency thereof. The views and opinions of authors expressed herein do not necessarily state or reflect those of the United States Government or any agency thereof. 


\title{
A DESIGN FOR A HIGH VOLTAGE MAGNET COIL RINGER TEST SET
}

\author{
Wayne Koska ${ }^{1}$ and Richard E. Sims ${ }^{2}$ \\ 1Fermilab National Accelerator Laboratory * \\ Box 500 \\ Batavia, IL 60510 \\ 2 Superconducting Super Collider Laboratory * \\ M.S. 1003 \\ 2250 Beckleymeade Avenue \\ Dallas, TX 75237
}

\begin{abstract}
By discharging a bank of charged capacitors through a high power SCR switch into an SSC dipole magnet assembly, it is possible to "ring" the coil and develop a voltage stress of greater than 50 volts turn-to-turn, thereby verifying the insulation integrity. We will present an overview of the test set design for a $2 \mathrm{kV}$ isolated SCR firing circuit, including safety features, selectable capacitor banks, and digital waveform storage system. Results from testing typical coils and magnets will be included. Possible upgrades are also discussed.
\end{abstract}

\section{INTRODUCTION}

Superconducting accelerator magnets require good insulation integrity between coils, and between the individual turns of the cable in a coil, since a quench which occurs in a magnet which is a component of a string may induce in the other magnets in the string potential differences on the order of hundreds of volts between cables, or a kilovolt or more between coils at the mid-plane. If arcing should occur at these times the probability of permanent damage to the magnet is high. During construction, magnets are continually tested for electrical shorts using resistance measurements and DC hipots. However, the potential differences developed between individual turns of a coil, (or between coils once they have been bussed together) during these tests are less than 1 volt, and therefore cannot determine if a situation exists where the insulation between two conductors is damaged to the point where it cannot stand-off the voltages to which it will be exposed during operation. The common way to test for this situation is to discharge a capacitor across the coil. This will be referred to as a "ring test", and has been used extensively at the Brookhaven National Laboratory 1 and at Fermilab 2 . Since the voltage dropped across the coil in this situation is inductive, it will divide evenly across the individual turns. For a capacitor charged to 2000 V, and an SSC Collider Dipole magnet with 90 turns, a potential difference of 22 volts will be developed across individual turns. In addition, the midplane insulation between the inner coils will be stressed to the full $2000 \mathrm{~V}$.

\footnotetext{
* Operated by the Universities Research Association, Inc., for the U.S. Department of Energy.
} 


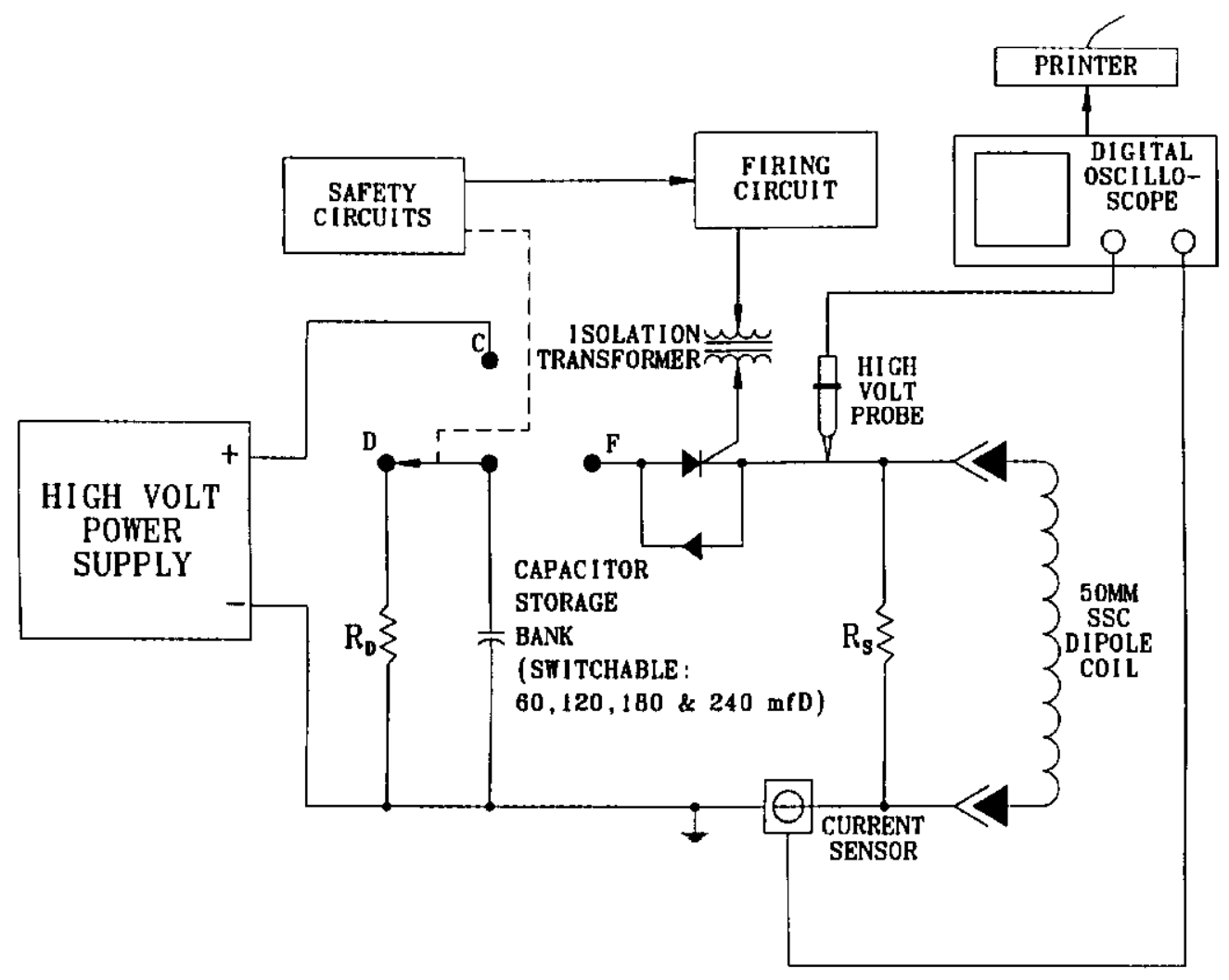

BASIC SCHEMATIC OF COIL RINGING TEST SET

Figure 1. The basic components of the high voltage coil ringing test set.

This paper will discuss the high voltage coil ringing test set developed at Fermilab for production testing of SSC Collider Dipole magnets. This device uses an SCR switch to connect the charged capacitors to the test coil instead of the more commonly used mercury relay. Since this unit is used on the production floor, considerable effort has been made to make it safe and easy to use for the technicians performing the tests. We will also discuss the technique established for determining if a coil or magnet is satisfactory.

\section{PRACTICAL CIRCUIT DESCRIPTION}

Figure 1 is a simplified schematic of the coil ringing test set ${ }^{3}$. The basic components are the high voltage power supply, the switchable capacitor bank, the SCR-diode combination which is used to connect the capacitor bank to the test coil, the SCR firing circuit, the digital display oscilloscope, and the safety circuits.

The power supply 4 charges a bank of three, six or nine $20 \mu \mathrm{f}$ bipolar capacitors 5 . The capacitors are connected to the test coil via a parallel SCR-diode combination. The SCR diode 6 combination makes it possible for current to flow in both directions in the LCR circuit. The SCR is fired using a 6 volt, $500 \mathrm{~mA}$ pulse of width $30 \mu \mathrm{s}$ produced by a toroid type isolated transformer7. The digitizing oscilloscope 8 is used to record, store and compare the voltage waveforms produced during the ring test. The safety circuits are described in detail below.

The major concern of a practical ringer circuit is safety. Charging capacitors of up to 240 microfarads with up to 2000 volts and discharging this much energy into a coil laying on an insulated workbench demands that a number of conditions be monitored by "safety 
circuits". Before the capacitors are charged, the following conditions are tested by the safety circuits:

1) Is the circuit connected to an earth (building) ground via a heavy braided cable and clamp?

2) Is the coil (or magnet) under test connected to the tester via heavy welding cable and "vise grip" type clamps? The circuit must read less than about $30 \mathrm{ohms}$ to pass this test.

3) Is the door on the back of the tester closed?

4) Has the tester circuit been reset? (This clears any previous test conditions and declares an intent to charge for a new test).

5) Is the emergency stop palm button reset?

6) Is the high voltage power supply "status OK" line true?

7) Are both "fire" buttons released?

When all these conditions are true, the "OK to charge" green light is on, and all red and yellow lighted buttons and indicators are off. The "charge" button may then be pressed which switches the capacitors from a discharging resistor ${ }^{9}\left(\mathbf{R}_{\mathbf{d}}\right)$ to the high voltage pulsed current power supply. When the capacitor voltage equals the programmed value, the power supply is disconnected and an "at set voltage" legend and two "fire" buttons light up green. A Sonalert brand alarm has also switched from a pulsed sound to a continuous sound to warn that the capacitors are charged and may be fired.

The operator now has about 20 seconds to press both "fire" buttons. The buttons are spaced far enough apart to require two hands, and the buttons must be depressed within $1 / 2$

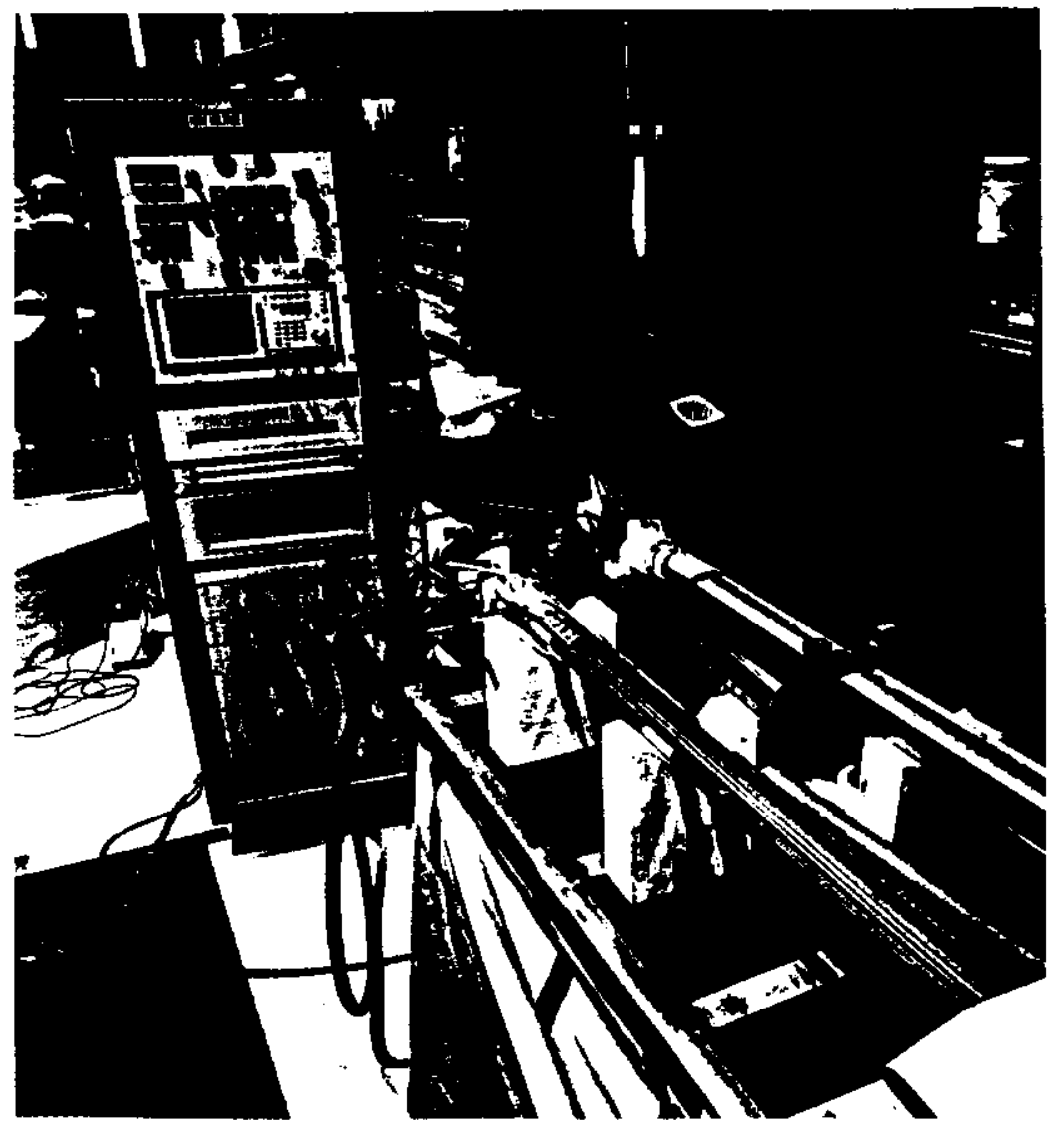

Figure 2. The ringer test set in use, testing an SSC Collider Dipole coil. 
second of each other to activate the firing circuit. If the operator does not fire the tester within 20 seconds, the capacitors are automatically switched back to the discharge resistor and the yellow "time out" and "discharged" lights come on and all green lights go out. The tester must now be reset to charge again.

If any of the original conditions were to become false during the charged period, the tester would revert to the discharged condition. Thus, if one of the coil connection clamps became disconnected, or the earth ground opened while in the charged state, the tester would dump the charge into resistor $\mathbf{R} \mathbf{d}$.

In a normal firing sequence the firing circuit would pulse the SCR gate at a 10 kilohertz rate, turning on the SCR and starting current flow through the coil under test. The SCR continues to conduct until the current drops below a critical limit, at which time the voltage across the capacitor bank has reached a maximum value with reversed polarity relative to the original conditions. The current flow then reverses, now flowing through the diode which is in parallel with the SCR. Again, when the current stops flowing in the reverse direction, the SCR is turned back on by the gate pulses and the forward current flow begins again. Due to resistive losses, each oscillation is lower in amplitude than the preceding one until, after several cycles, there is not enough current to exceed the holding current of the SCR and current flow ceases. The discharge light comes on and the operator turns up the charge voltage to the next specified step, presses "reset", and then "charge" to continue the test. Figure 2 is a photograph of the ringer test set in the process of testing an SSC Collider Dipole coil.

\section{CHARACTERISTICS OF FAILURE MODES}

When a capacitor, of capacitance $C$, is discharged across a coil with inductance $L$ and resistance $R$, the voltage measured across the capacitor varies as:

$$
V=V_{O} e^{-\frac{\gamma t}{2}} \cos (\omega t+\alpha)
$$

where

$$
\gamma=\frac{R}{L}, \omega=\frac{1}{\sqrt{L C}}\left(1-\frac{1}{4 Q^{2}}\right)^{1 / 2}, Q=\frac{1}{R} \sqrt{\frac{L}{C}}
$$

A change in inductance due to the development of an electrical short developing between two adjacent cable turns will result in a change in the resonant frequency of the LCR circuit. It is this shift in frequency which we are trying to detect. Figure 3 displays a calculation of the shift in frequency which can be expected if the inductance of an SSC inner coil decreases by $5 \%$ due to a short when the maximum discharge voltage was 1000 volts relative to a similar discharge at 500 volts. Of course, the $Q$ of the circuit may also change due to the short, which would also affect the ring frequency. A discussion of the frequency shift which might be expected from changes in both these parameters may be found in reference 10 . In addition to a shift in frequency, erratic behavior of the voltage waveform, such as dips, spikes or kinks, may be indications of arcingl. If an arc occurs near the end of a magnet it is likely that it will be heard by the technician performing the test.

\section{TEST PROCEDURE}

A standard procedure for performing ring tests on production magnets has been developed. Prior to performing a ring test, DC hipot tests are performed where applicable. Then the inductance and $Q$ of the coil or magnet assembly are measured at approximately the resonant frequency of the ringer circuit. The resonant frequency is then calculated. The ringer capacitors are charged to a low voltage, typically $100 \mathrm{~V}$, and discharged into the coil. The waveform is recorded with a digital oscilloscope and the measured frequency compared to the calculated value. We have found that the measured frequency is very sensitive to the calibration of the high voltage probes used, so it may differ from the calculated value by up to $20 \mathrm{~Hz}$. If the difference is significantly greater than this, additional tests are performed to 


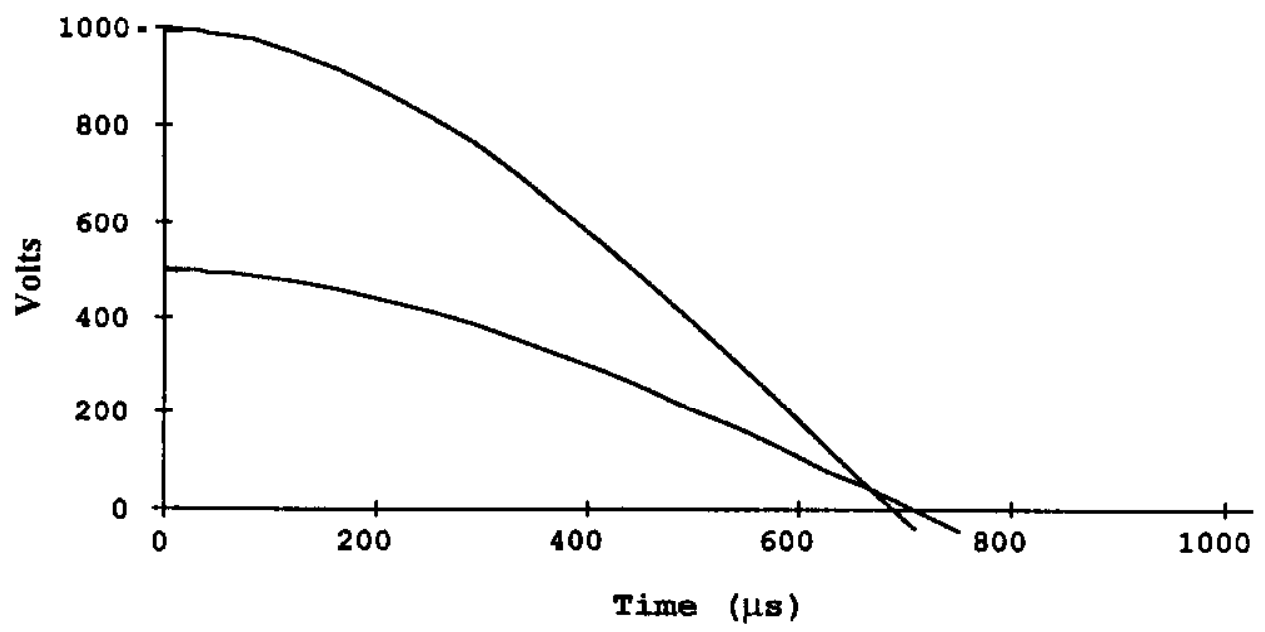

Figure 3. The calculated response of an SSC inner coil, with nominal inductance, to a ring at 500 volts, and the response with inductance reduced by $5 \%$, to simulate a turn to turn electrical short, at 1000 volts. The shift in the zero volt crossing point is obvious.

determine the reason before subjecting the coils to higher voltages. Otherwise this waveform is stored and used as the baseline. A series of rings with progressively higher maximum discharge voltages are then performed and the resulting waveforms are stored in memory in the display oscilloscope and overlaid on the screen. The zero voltage crossing points are examined for any indication of a shift in the resonant frequency as the discharge voltage is increased. The shape of the waveforms are also examined for erratic behavior.

Ring tests are performed at critical stages in the assembly of a magnet. Each coil is tested after it is cured. These tests are performed at 100,500 and 1000 volts and produce a maximum turn to turn potential difference of $53 \mathrm{~V}(38 \mathrm{~V})$ for inner (outer) coils. Figure 4 shows the results of a ring test performed on a $50 \mathrm{~mm}$ aperture SSC Collider Dipole inner

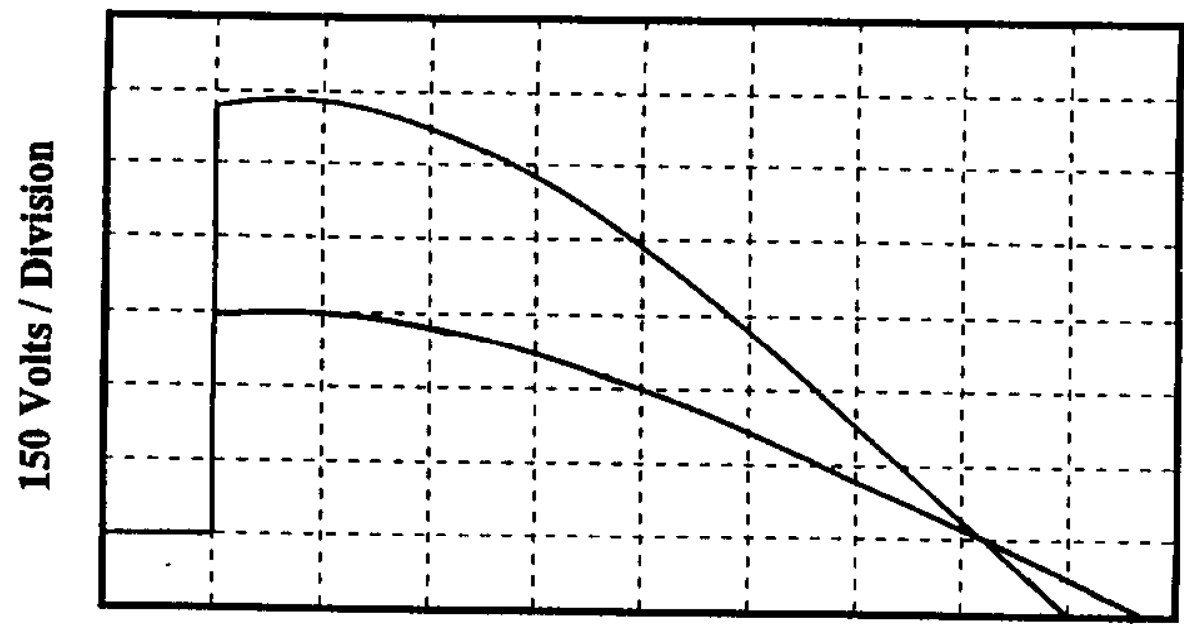

$100 \mu \mathrm{s} /$ Division

Figure 4. The voltage traces which resulted from ringing an SSC collider dipole inner coil. 


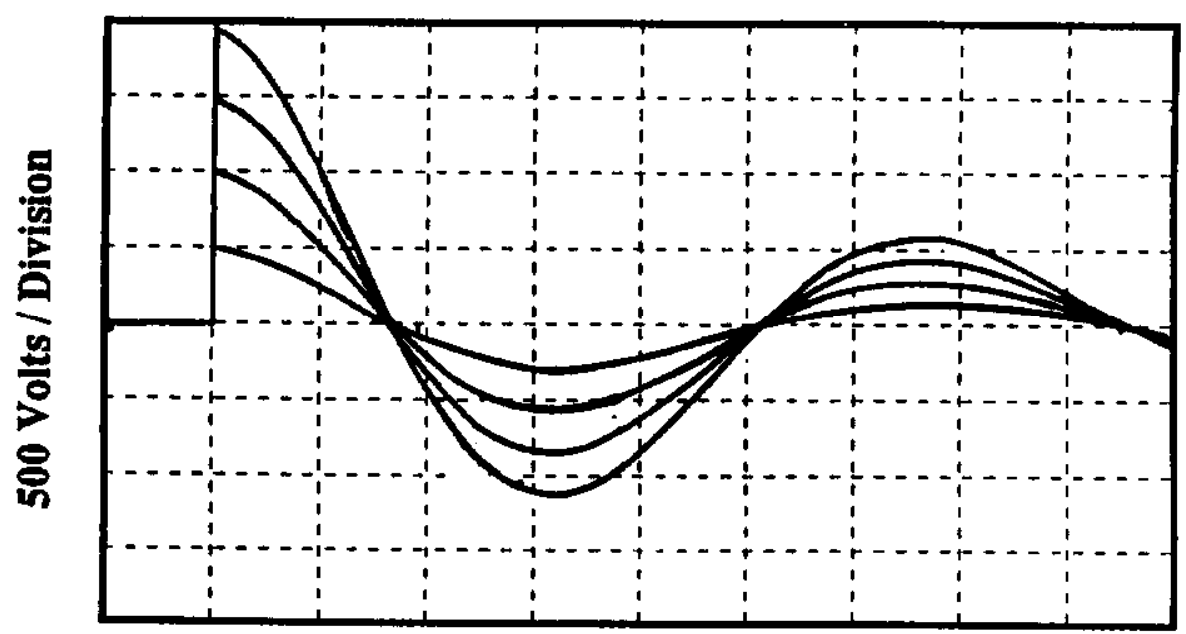

2 ms / Division

Figure 5. The voltage traces which resulted from the final ring test performed on SSC collider dipole magnet DCA319, prior to shipment to the test facility.

coil. The convergence of the traces at the zero volt crossing point indicates that this coil has acceptable cable to cable insulation integrity. The assembled coils are next rung after the keying operation, which is the step at which the coils were exposed to their maximum stress. The upper to lower splice is still accessible at this time so that the upper coils and lower coils can be rung separately. The maximum discharge voltage is 2000 volts resulting in a turn to turn voltage of 44 volts. The test is next performed after the shell has been welded in place; when the cold mass is essentially completed. A final test is performed just prior to shipment to the test facility to determine if the insulation integrity has degraded during the time the magnet was being cryostated. These latter tests are performed with a series of discharges beginning at 500 volts and increasing in $500 \mathrm{~V}$ steps to 2000 volts. The maximum tum to turn voltage is $23 \mathrm{~V}$. In addition, the potential difference across the inner coil midplane insulation is $2000 \mathrm{~V}$. Figure 5 shows the final ring test performed on the SSC collider dipole magnet DCA319. Again the traces converge at the zero crossing points, indicating that the insulation integrity of this magnet is satisfactory.

\section{POSSIBLE UPGRADES}

The voltage developed between individual cable turns when ringing fully bussed magnets is marginal for discovering faults. Much of the design for a $5 \mathrm{kV}$ ringer ${ }^{11}$, which can be implemented by firing three series connected 2200 volt peak rated SCRs with a three secondary winding transformer, has been completed 12. All three SCRs must be fired and must turn off within nanoseconds of each other to divide the 5000 volts equally. Commutation capacitors across each SCR helps this situation. However, at high frequencies the coils in a magnet behave like a transmission line so that the high frequency components of the ringer pulse, to which the magnet is exposed when the SCRs switch on, cause the early turns of the magnet to experience transient voltages $(\approx 10 \mu \mathrm{s}$ long) on the order of 10 times higher than the value obtained by dividing the whole coil voltage by the number of turns. At very high maximum ringer voltages this would over stress the turn to turn insulation of the coils. Initial modeling of the ringer-magnet circuit 13 indicate that a high current, low inductance resistive choke coil inserted between the SCR and 
magnet would greatly reduce these high frequency components. Further study will need to done on this problem before a $5 \mathrm{kV}$ ringer test set can be used to routinely test magnets.

A second improvement to the current high voltage ringer test set would be to control the oscilloscope through a computer. This would allow the digital oscilloscope to be automatically programmed for each test sequence and magnet situation, as well as providing a means to collect the data, perform a routine analysis, and produce a test report.

\section{SUMMARY}

A high voltage coil ringing test set has been developed at Fermilab for the production testing of SSC Collider Dipole Magnets. Emphasis has been put on building a system that is safe and easy to use for the technicians performing the tests. Ring tests are performed on each individual coil prior to packaging as a magnet, then on the coil assemblies after they have been keyed (this is after the coils have been subjected to maximum stress during the keying process), after the magnet shell has been welded around the yokes and just prior to shipping the magnet to test. Only one fault has been detected with this system in the $50 \mathrm{~mm}$ dipole magnet program at Fermilab. This was a lead to ground arc caused by improper insulation of the lead. It was easily repaired. Our experience during the SSC magnet program at Fermilab is that the high voltage ringer test is useful for exposing assembly problems early and has never damaged a coil or magnet that was not already defective.

\section{ACKNOWLEDGEMENTS}

A number of people have helped with the design of the ringer test set and the procedures developed to test SSC magnets at Fermilab. We would like to acknowledge the work of Donna Kubik, Richard Gaf, Dennis Gaw and Eric Schmitz. We would also like to thank Jim Strait for his suggestions during the early development of this equipment.

\footnotetext{
${ }^{1}$ G.G. Sintchak, J.G. Cottingham, and G.G. Ganetis, Electrical Insulation Requirements and Test Procedures for SSC Dipole Magnets, Supercollider 2, 397, (1990) M. McAshan, ed.

2 P. Mazur, private communication.

3 The Fermilab drawing number for the 2000 Volt Ringer is 0102-ME-301504.

4 The power supply used was a CCS-200-5-P manufactured by Converter Power Inc. (part \# CCS-200-5-P).

5 These were $20 \mu f, 7.5 \mathrm{kV}$ capacitors, manufactured by Maxwell Laboratories, Inc. (part \# 30665). The high voltage capacitor transfer relays were manufactured by Ross Engineering Corp. (part \#E15DT15-1-0)

6 The SCR was manufactured by Powerex, Youngwood, PA (part \# T700223504) and is rated at 2200 volts at 350 amps. The diode was manufactured by Powerex (part \# R6002630XYA) and is rated at 2600 volts at 300 amps.

7 The toroid core used in the firing circuit was manufactured by Magnetics Co. Inc. (part \# 58110-A2, $\mathrm{MU}=60$, distributed gap). It was modified by adding 200 turns of $\# 20$ wire to both the primary and secondary windings.

8 The oscilloscope used was a Hewlett Packard model 54501A with a model 1137A $5000 \mathrm{~V}$ probe.

${ }^{9}$ High voltage, non-inductive resistors were obtained from Chaddock Electronics, Inc.

$10 \mathrm{~W}$. Koska, The Ringing Technique for Determining Turn to Turn Electrical Shorts in SSC Collider Dipole Magnets-Parts 1, 2 and 3. TS-SSC 92-029, TS-SSC 92-030 and

TS-SSC 92-031

11 The Fermilab drawing number for the $5 \mathrm{kV}$ ringer is 0102-ME-290707.

12 If three SCRs are to be used in series, they must be matched in leakage and stored charge $\left(\mathrm{Q}_{\mathrm{rr}}\right)$. It is possible that a single high voltage SCR manufactured by GE-SPCO, Malvem, PA. (Part \# C716) may be used for service up to $\mathbf{4 8 0 0}$ working volts. The firing circuit may have to be modified to supply proper voltage and current to the gate for this device.

13 E. Schmitz, Electrical Modelling of Magnets-Upper Inner Section, TS-SSC 91-231, 11/27/91, and Electrical Modelling of Magnets-Long Time-Scale, TS-SSC 91-247, 12/12/91.
} 